\title{
Contribution to the modelling of interfaces in masonry construction
}

\author{
Fazia Fouchal ${ }^{\mathrm{a}, \mathrm{b}}$, Frédéric Lebon ${ }^{\mathrm{a}}$, Isabelle Titeux ${ }^{\mathrm{b}, *}$ \\ a LMA UPR-CNRS 7051, Université Aix-Marseille 1, 13402 Marseille Cedex 20, France \\ ${ }^{\mathrm{b}}$ GRESPI EA 4301, Université de Reims, 51687 Reims, France
}

\begin{abstract}
The aim of this study was to model the mechanical behavior of interfaces in masonry structures. In the first part, the characteristics of the materials and interfaces involved are determined experimentally. In the second part, a model based on the adhesion intensity is developed. This model can be used to describe the interfaces between mortar and full or hollow bricks and to describe the damage occuring in the mortar. The mechanical behavior predicted by this model is compared with previously obtained experimental data. The model is then tested in the case of some classical masonry structures (small walls, diagonal compression tests).
\end{abstract}

keywords: Masonry, Interfaces, Modelling, Damage, Cracks

\section{Introduction}

The seismic vulnerability of masonry buildings is known to depend strongly on their resistance to shear forces. When out-ofplane failure is prevented by using suitable devices, the structural reliability can be predicted and appropriate strengthening techniques adopted on the basis of the known in-plane shear behavior. It is therefore of great interest to model and test the shear responses of building components subjected to horizontal cyclic loading conditions [1,2]; these responses are usually characterized by a peak load, loss of rigidity and energy dissipation [3]. Some models have been previously presented in the literature, in which the wall is taken to be a single structural element characterized by a non-linear response when exposed to shear forces [4]. In this context, some information can be obtained about the lateral strength, using continuous models for a medium with no tensile strength [5] or using the low rupture approach [6]. Since masonry is a composite structure, however, failure of these structures will depend on the properties of the materials (mortar, bricks, etc.), as well as on the characteristics of the bonding between the various components. Many modelling studies have been carried out on masonry interfaces. Gambarotta and Lagomarsino [7], for instance, developed a damage model predicting the responses of

\footnotetext{
* Corresponding author.

E-mail addresses: fouchal@lma.cnrs-mrs.fr (F. Fouchal), lebon@lma.cnrs-mrs.fr (F. Lebon), isabelle.titeux@univ-reims.fr (I. Titeux).
}

brick walls subjected to cyclic loads. The main advantage of this model is that it deals with the mechanical behavior of each component of the masonry as well as the interface. A "fragile behavior" law has been used for bricks and a specific law for mortar, which depends on the decohesion and sliding properties. The latter law was established on the basis of two internal variables accounting for the sliding with friction and damage in mortar joints. Raous, Cangémi and Cocou [8] have developed a model, called the RCCM model, predicting the evolution of damage at the interface between two initially bonded deformable bodies. These authors addressed the transition problem from the adhesive state to a friction state (in the tangential plane of the interface) and to a unilateral contact state (in the normal direction with respect to the interface). This model will be adopted here.

The first part of this paper deals with the experimental characterization of the materials (bricks and mortar) and the brick/mortar interface. It is proposed first to characterize the masonry materials involved. We will then describe experimental studies on the shear behavior of masonry on the local scale, in the case of two different assemblies composed of two and three full/hollow bricks. The results of an experimental campaign are presented and discussed.

The second part of this paper deals with the numerical modelling. The mechanical modelling approach (and in particular the RCCM model adopted) is first presented. The numerical procedure used is then described. Lastly, some numerical examples are given and compared with the experimental data. 


\section{Experimental results}

\subsection{Characterization of materials}

\subsubsection{Mortar}

The mortar used in this experimental study was a ready-to-use mortar based on sand and cement supplied by the firm Weber and Broutin. The elastic modulus (4000 MPa) and the Poisson's ratio (0.3), which are used in the numerical study, are given in [9].

\subsubsection{Bricks}

The fired earth bricks used for the present experimental tests were either full or hollow. The dimensions of each brick was

Table 1

Loading rate.

\begin{tabular}{ll}
\hline Predicted strength $\left(\mathrm{N} / \mathrm{mm}^{2}\right)$ & Loading rate $\left(\mathrm{N} / \mathrm{mm}^{2}\right) / \mathrm{s}$ \\
\hline$<10$ & 0.05 \\
From 11 to 20 & 0.15 \\
From 21 to 40 & 0.3 \\
From 41 to 80 & 0.6 \\
$>80$ & 1.0 \\
\hline
\end{tabular}

Prism 1

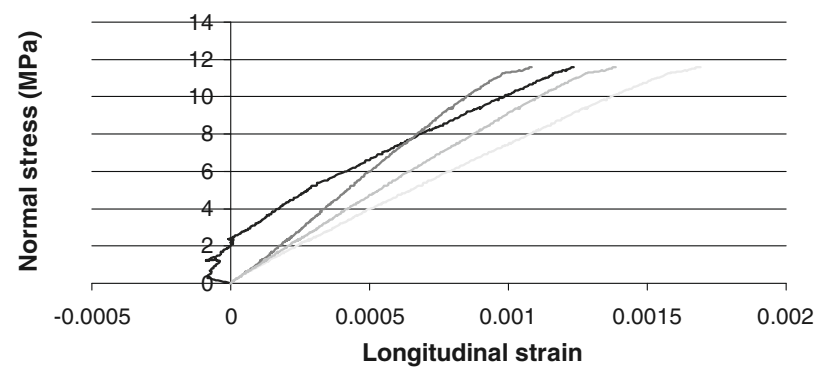

Prism 2

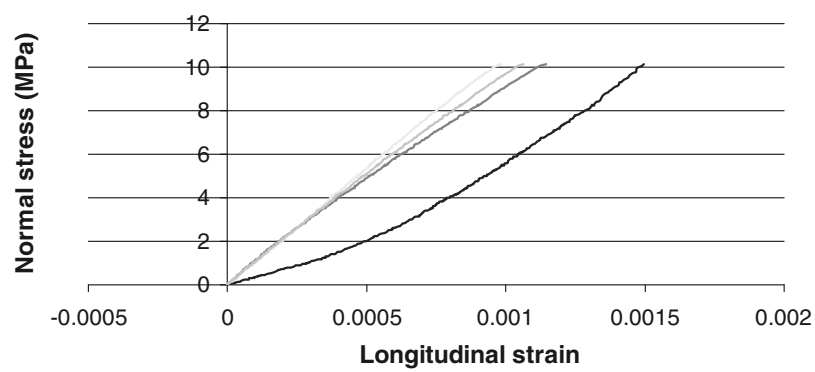

Prism 3

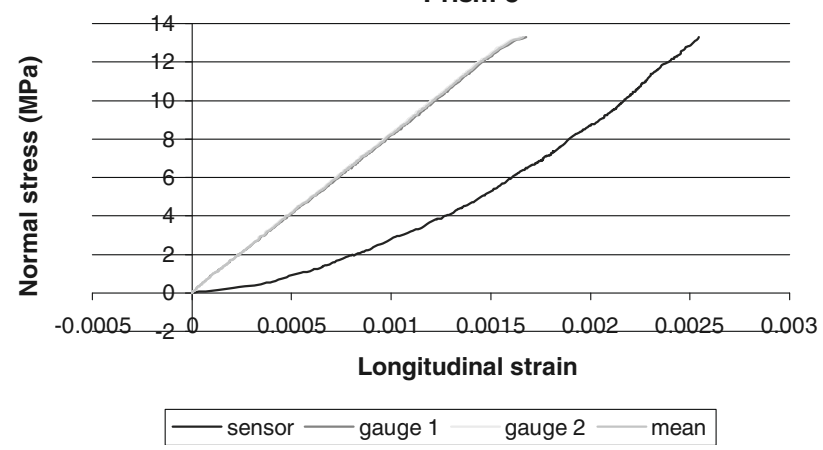

$210 \mathrm{~mm}$ (length) $\times 100 \mathrm{~mm}$ (width) $\times 50 \mathrm{~mm}$ (height). Ten holes in the bricks $25 \times 25 \mathrm{~mm}^{2}$ in size were arranged in two rows. A compression test based on standard NF EN 772-1 [10] was carried out on series of three full/hollow bricks in order to determine the compression strength, the elastic modulus and the Poisson's coefficient of the masonry units. The load was imposed up to failure in two steps: the load was gradually increased as shown in Table 1 ; half-way to the maximum pressure, the load was increased in order to reach the maximum pressure within $1 \mathrm{~min}$.

The normal compression load was applied to the upper face of the bricks and gauges were glued to the bricks in the transversal and longitudinal directions (unidirectional compression tests). An extensometric sensor was also fixed to the bricks. The elastic modulus was determined from the strain-stress curve at $30 \%$ of the final load.

Full and hollow bricks were used. Three tests are carried out on each kind of brick. The curves giving the longitudinal deformation with respect to the normal stress and the transversal deformation with respect to the normal stress are shown in Figs. 1 and 2.

The quantitative data obtained on the above mechanical parameters are summarize in Tables 2 and 3.

The experimental results obtained were similar to the mean value recorded by the two gauges. The dispersion of the results was very small.
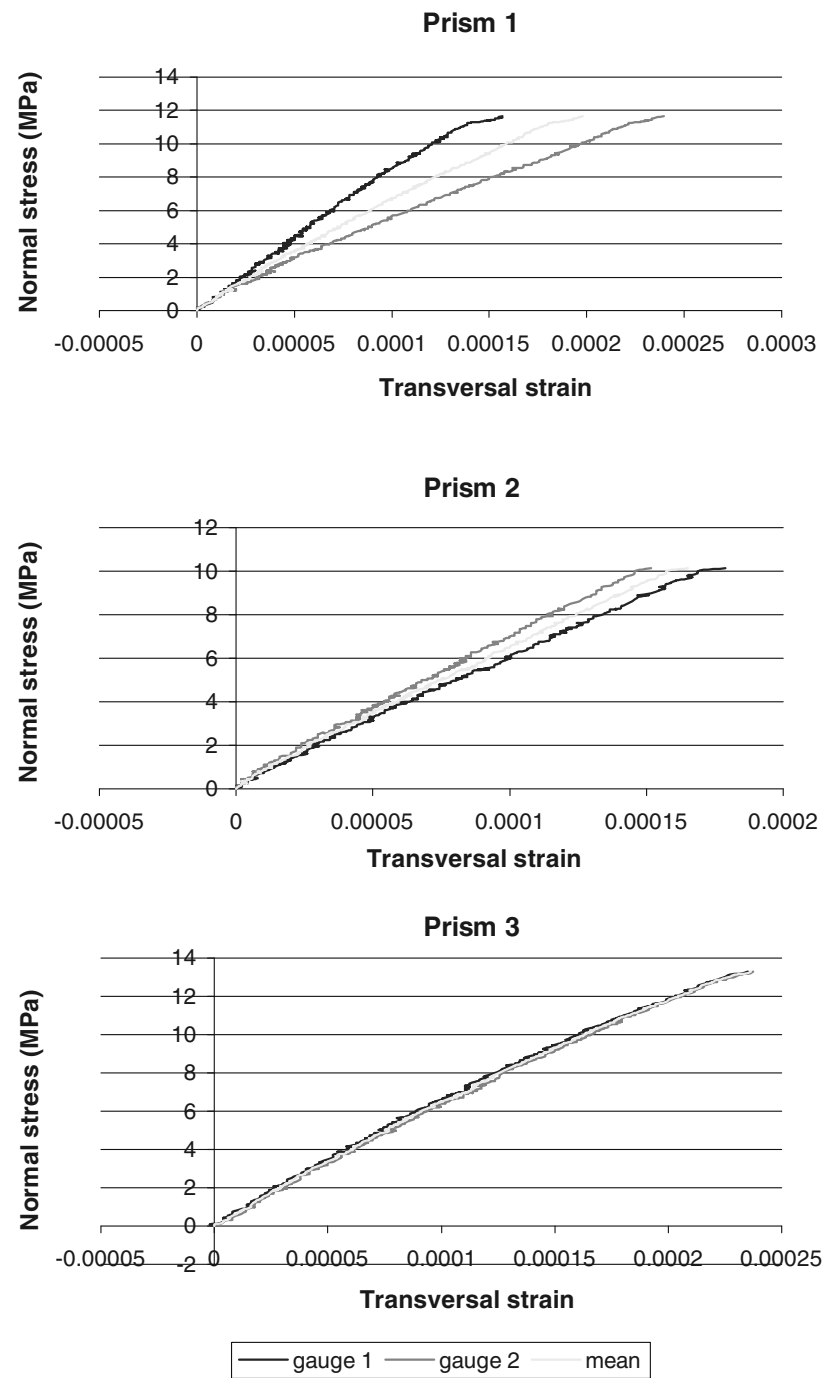

Fig. 1. Compression test on full bricks: elastic modulus and Poisson's coefficient. 
Prism 1

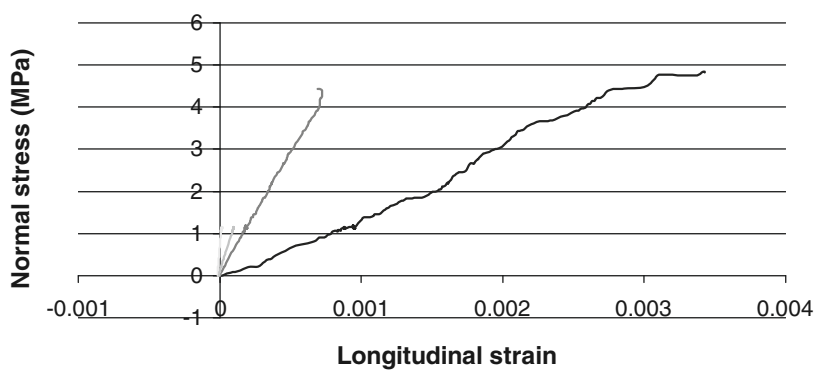

Prism 2

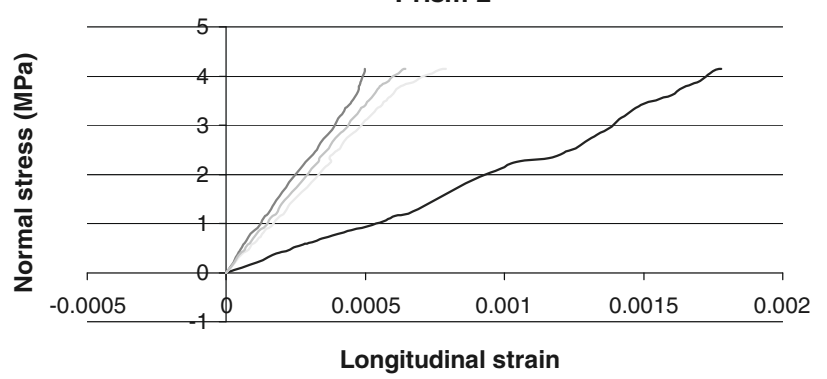

Prism 3

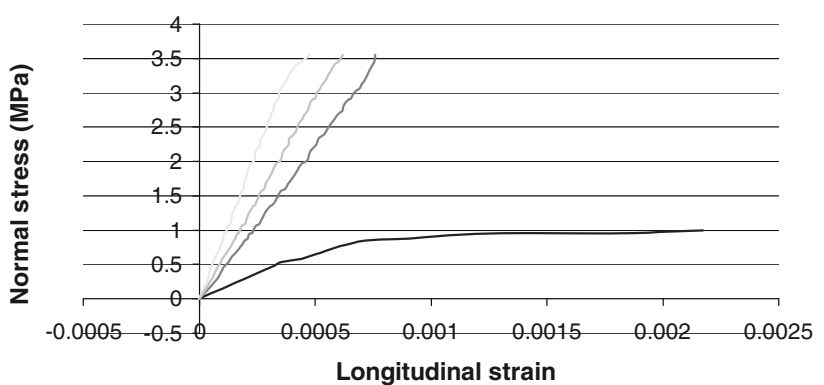

Longitudinal strain

- sensor - gauge $1-$ gauge $2 \longleftarrow$ mean
Prism 1

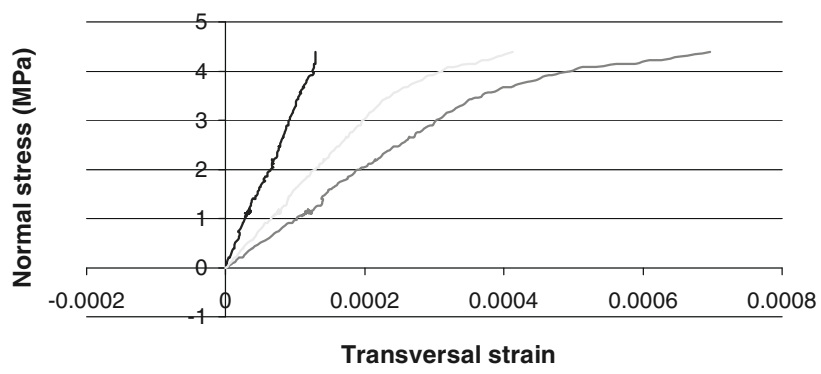

Prism 2

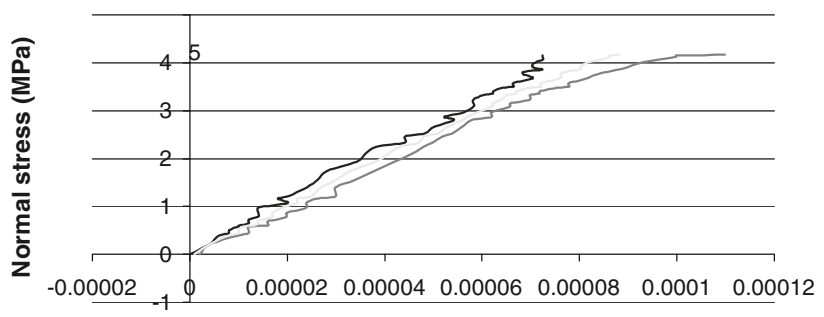

Transversal strain

Prism 3

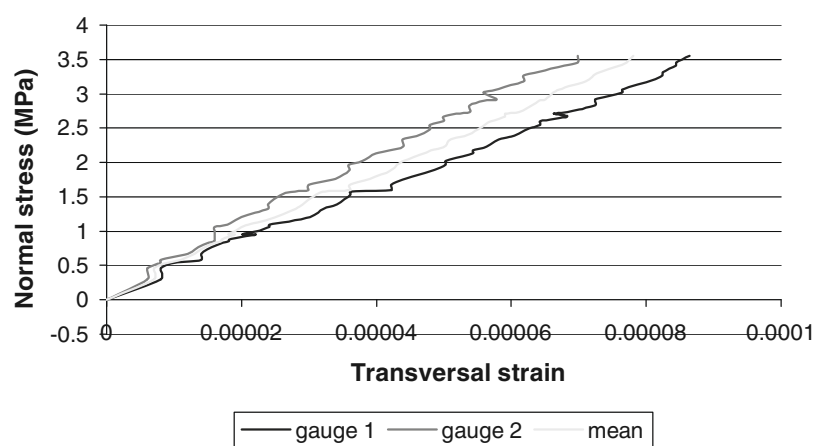

Fig. 2. Compression test on hollow bricks: elastic modulus and Poisson's coefficient.

\subsection{Mechanical behavior of small assemblages under shear loading conditions}

In order to determine the influence of the unit volume, two kinds of prism were tested. Those of the first kind were composed of two bricks, and those of the second kind were composed of three bricks. With each kind of prism, both full and hollow bricks were tested. The aim of this study was to determine the shear behavior and the failure mode at the brick/mortar interface.

Prisms were prepared in line with standard NF EN 1052-3 [11]. The samples were subjected to a monotonously increasing load until damage occurred. The loading conditions were monitored during the test. The maximum strength reached during the test is called the rupture strength.

Table 2

Mechanical properties of full bricks.

\begin{tabular}{llrl}
\hline $\mathrm{Nb}$ & $\begin{array}{l}\text { Compression strength } \\
(\mathrm{MPa})\end{array}$ & $\begin{array}{l}\text { Elastic modulus } \\
(\mathrm{MPa})\end{array}$ & $\begin{array}{l}\text { Poisson's } \\
\text { coefficient }\end{array}$ \\
\hline 1 & 11.7 & 9439 & 0.13 \\
2 & 10.2 & 10447 & 0.14 \\
3 & 13.3 & 8429 & 0.13 \\
Mean & 11.7 & 9438 & 0.13 \\
$\quad$ value & & & \\
\hline
\end{tabular}

In order to establish a shear behavior law, curves giving the shear stress with respect to the relative displacement were plotted. The qualitative results obtained are presented and discussed below.

From the quantitative point of view, Fig. 3 (respectively 4) shows the displacements recorded with respect to the shear load. It is worth noting that the results were highly dispersed in the case of both two-brick and three-brick assemblages. This dispersion can reach $500 \%$ of the failure threshold in the case of three-hollowbrick structures. These differences can be explained by the rupture modes. In the case of hollow brick assemblages, these differences are amplified by the presence of mortar spikes in the brick at the mortar/brick interface (Fig. 4).

We can differentiate here between the following two kinds of rupture:

Table 3

Mechanical properties of hollow bricks.

\begin{tabular}{llll}
\hline $\mathrm{Nb}$ & $\begin{array}{l}\text { Compression strength } \\
(\mathrm{MPa})\end{array}$ & $\begin{array}{l}\text { Elastic modulus } \\
(\mathrm{MPa})\end{array}$ & $\begin{array}{l}\text { Poisson's } \\
\text { coefficient }\end{array}$ \\
\hline 1 & 4.4 & 5934 & 0.14 \\
2 & 4.4 & 6737 & 0.14 \\
3 & 4.6 & 5505 & 0.12 \\
$\begin{array}{l}\text { Mean } \\
\quad \text { value }\end{array}$ & 4.46 & 6059 & 0.13 \\
\hline
\end{tabular}



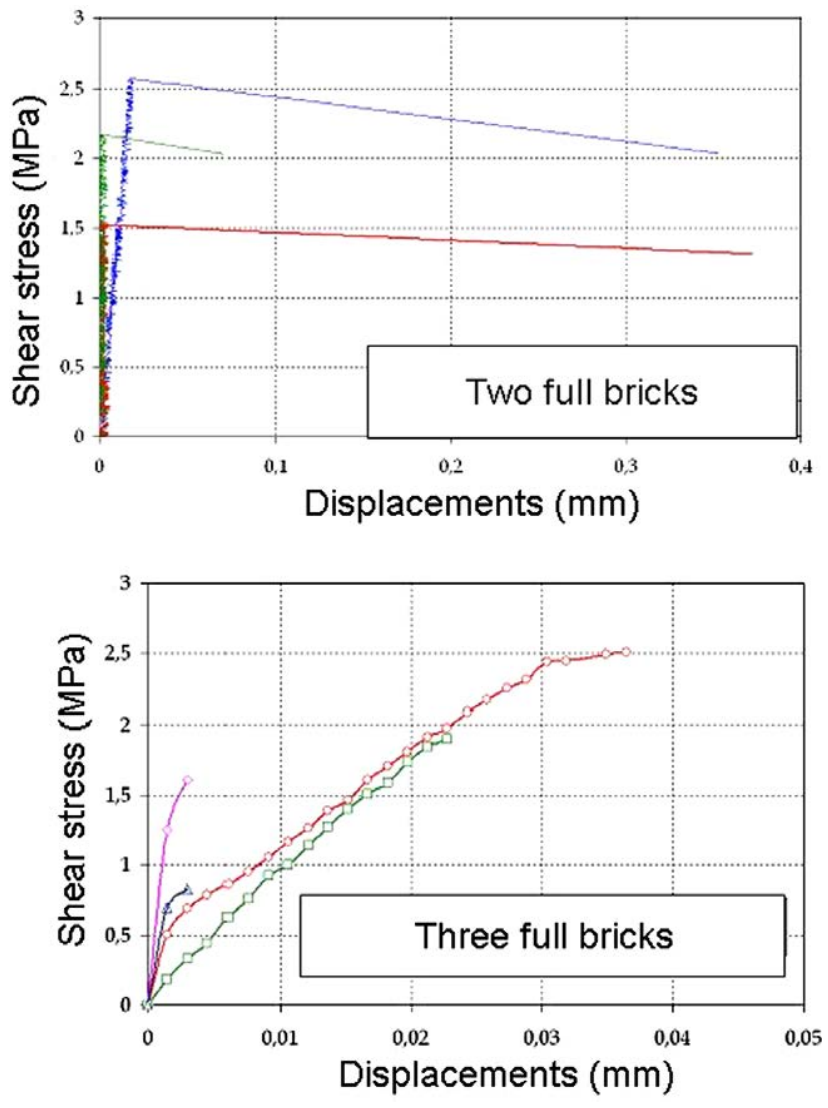

Fig. 3. Shear test on two full-brick and three full-brick prisms.
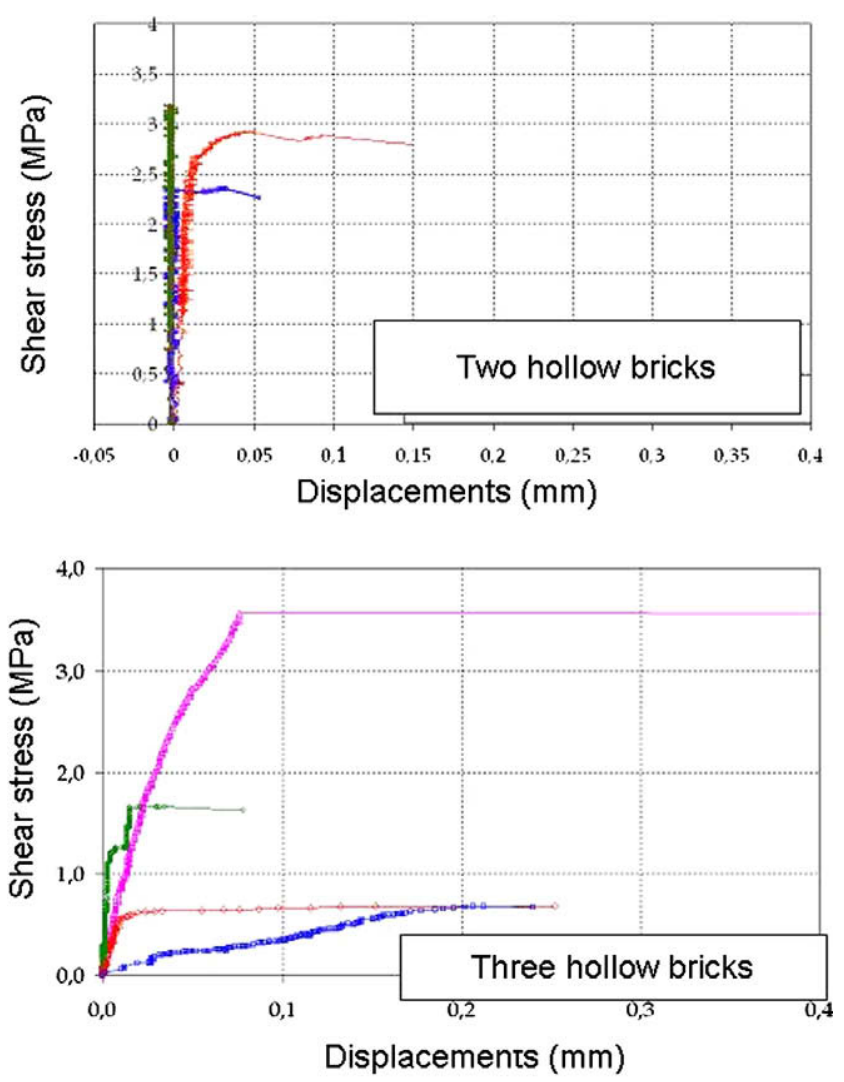

Fig. 4. Shear test on two hollow-brick prisms.

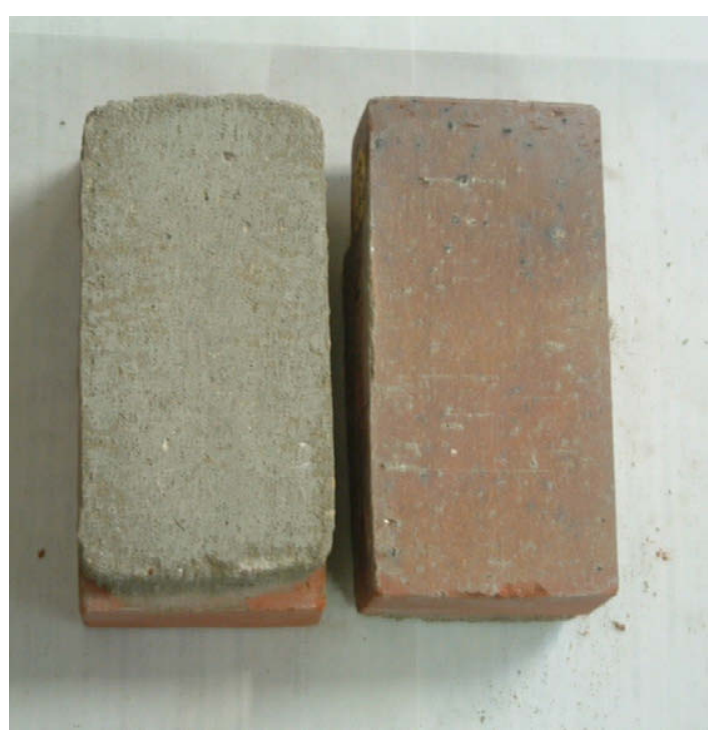

Fig. 5. Rupture mode in a specimen.

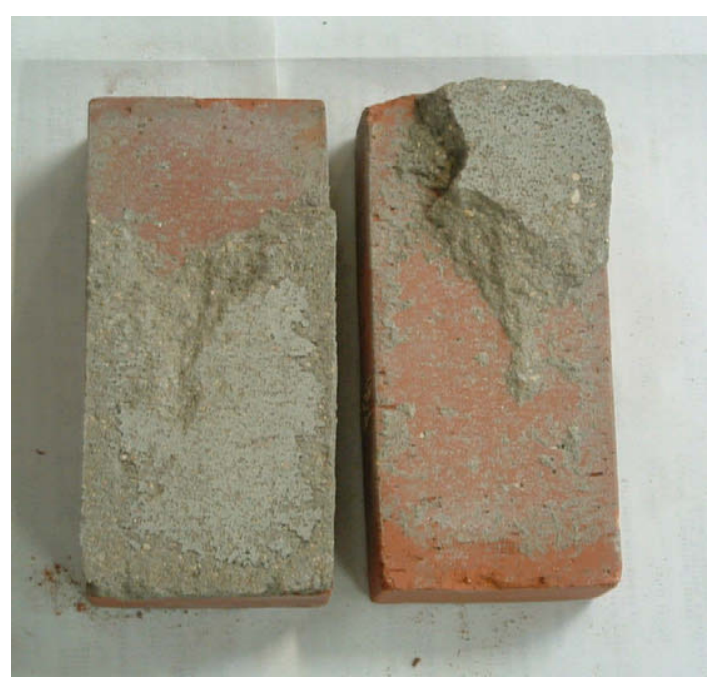

Fig. 6. Rupture mode in a specimen.

- rupture occurring along the mortar/brick interface (see Fig. 5),

- rupture beginning along the interface and crossing through the mortar layer (see Fig. 6).

The two kinds of rupture can be combined in a single assemblage as shown in Fig. 7.

With all the specimens tested, the results of the tests show that the mechanical behavior of the unit volumes is very stiff in the elastic domain. The order of magnitude of the displacement was only a few microns. The breaking stress point differed, depending on the kind of bricks (full or hollow).

When the maximum stress level was reached, we noted that the behavior of the full-brick specimens was fragile, contrary to the hollow-brick specimens, which were characterized by a (quasifragile) softening behavior and by a sliding movement between the adjacent bricks. This behavioral difference can be explained in the case of hollow bricks by the presence of spikes of mortar at the brick/mortar interface.

With identical assemblies consisting of the same materials under very similar conditions, the rupture stress point showed con- 


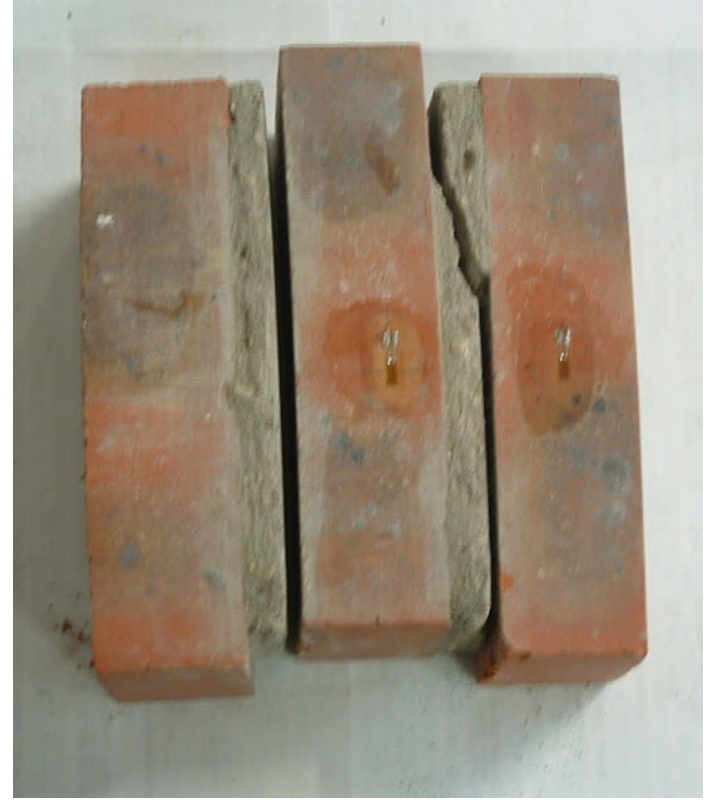

Fig. 7. Rupture mode in specimen.

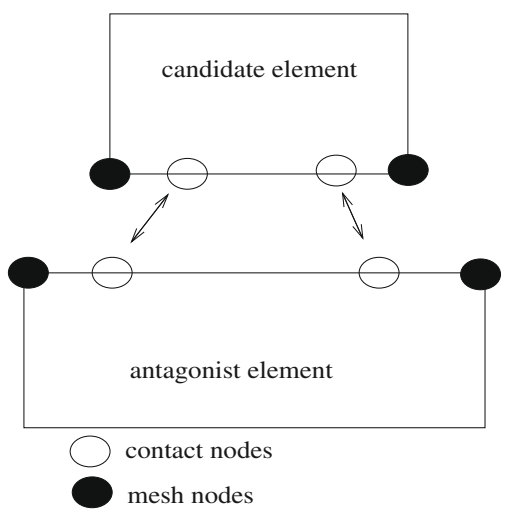

Fig. 8. Position of contact nodes between two bodies.

siderable dispersion, resulting in completely different rupture modes from one assembly to another: along the interface, crossing through the mortar or in the bricks themselves. These differences will be explained by analyzing the responses of the masonry specimens on the local scale, taking several external factors (such as human interventions) and internal factors into account, without checking the results experimentally. These local effects will presumably disappear if the masonry is analyzed on other more realistic scales.

Comparisons between the results obtained on couplets and triplets of full and hollow bricks showed that the magnitude of the stress failure point and that of the displacements were similar in both cases. It can therefore be concluded that couplets and triplets of specimens consisting of full and hollow bricks show similar behavior under shear stress loading conditions.

\section{Numerical modelling}

These experimental results on mortar, bricks and small assemblages show that the behavior of these components is characterized by non linearities. These results will be subsequently used to perform numerical computations.

In the structures studied here, rigid elastic behavior was observed up to failure point, followed by friction sliding behavior.

Since couplet and triplet samples were found to show similar behavior, the choice of basic unit will have no effect on the global scale. In the subsequent modelling study, only the interface will therefore be of importance, and not the basic components used.

The results obtained here on full/hollow brick samples show considerable dispersion, mainly due to the local failure modes (along the interface and across the mortar), and in the case of hollow bricks, to the non uniform distribution of the mortar spikes. The rupture process occurring across the mortar can be accounted for either by a motar damage model (see for example [12]) or by a cohesive zone model.

Having identified some of the factors on which the rupture of the masonry depends on the local scale and having characterized the mechanical properties of the materials and the corresponding constitutive equations, it is now proposed to model the interfaces involved in the framework of the laws mentioned in the Introduction.

\subsection{Theoretical mechanical problems}

To model the mortar/brick interfaces, we adopted the adhesion model known as the RCCM model [8,13] (Raous-Cangémi-CocouMonerie). As a matter of fact, with this interface model, it is possible to combine unilateral contact conditions (non penetration between the mortar and the brick), with friction and adhesion between two

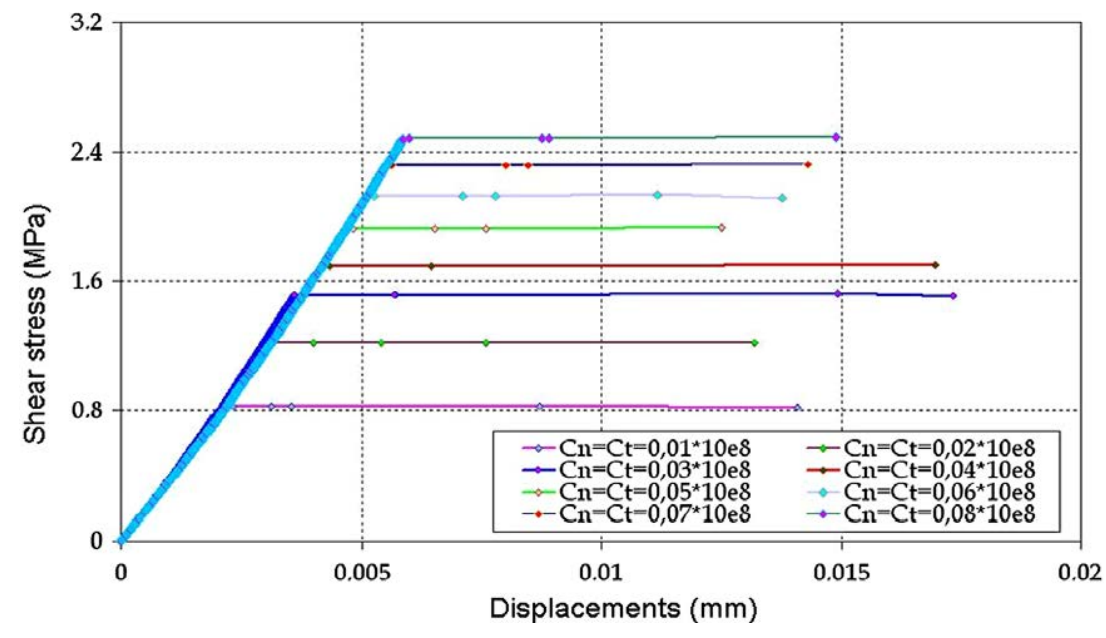

Fig. 9. Influence of parameters $C_{N}$ and $C_{T}$ on the behavior of full-brick triplets. 
deformable solids. For further details of the RCCM model, the reader is referred to $[8,13]$. The local constitutive equations required for this model are deduced from thermodynamic considerations and based on a material surface hypothesis about the contact zone. The basic idea underlying this model is to introduce a new state variable describing the contact state. This adhesion intensity variable,
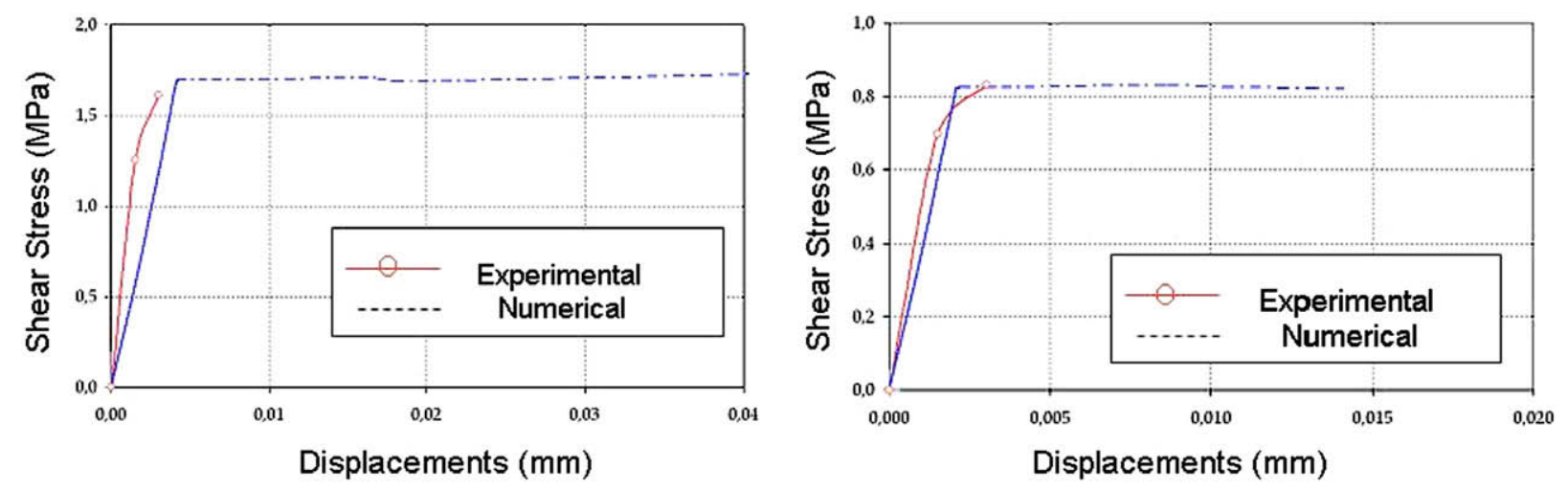

Fig. 10. Shear tests: tests $\mathrm{N} 1\left(C_{N}=C_{T}=4 \times 10^{6} \mathrm{~N} / \mathrm{mm}^{3}\right)$ and $\mathrm{N} 4\left(C_{N}=C_{T}=10^{6} \mathrm{~N} / \mathrm{mm}^{3}\right)$.
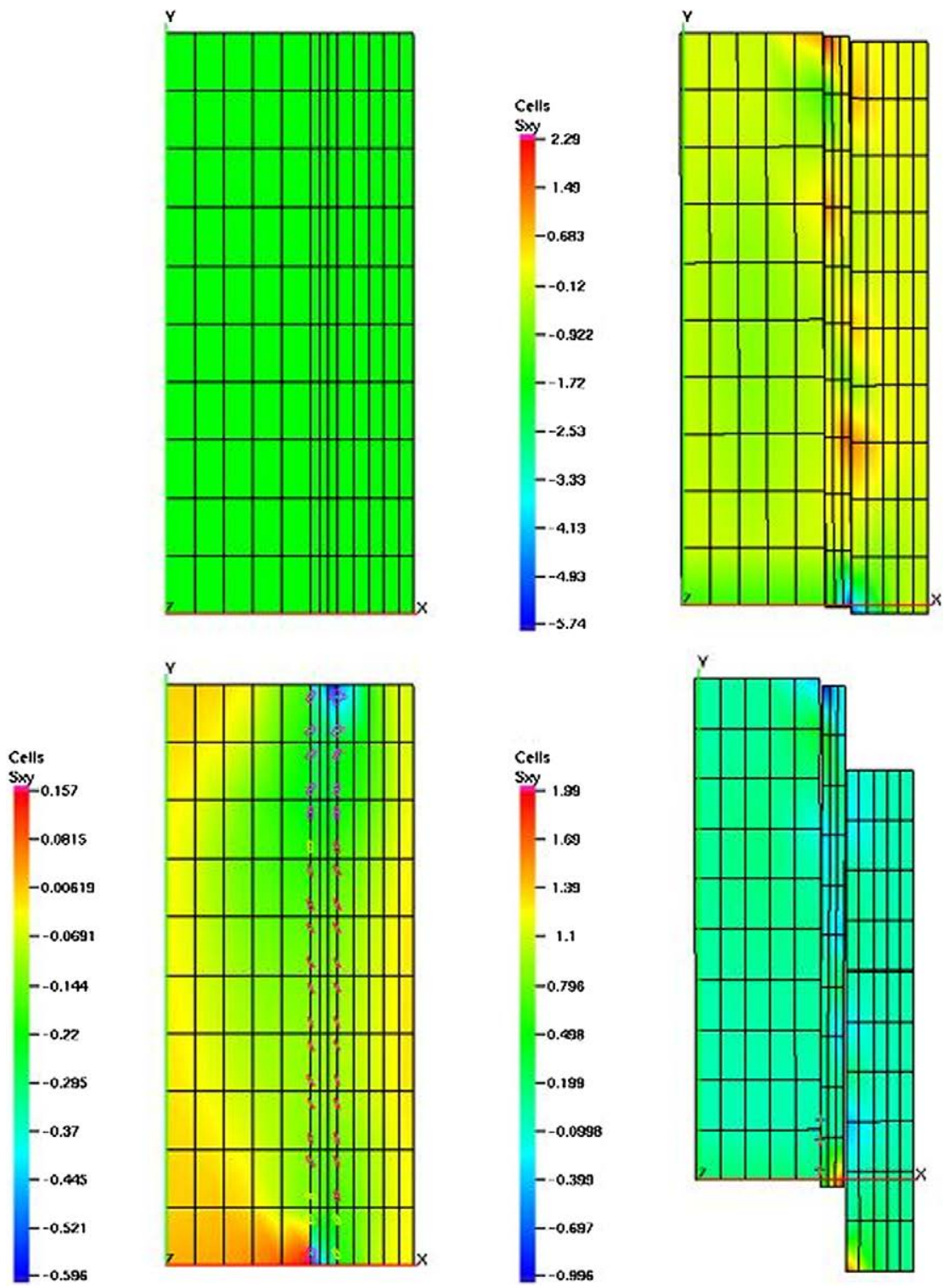

Fig. 11. Shear stress in full-brick triplets at steps 0, 100, 207 and 208. 
denoted $\beta$, was initially introduced by Frémond [14]. This variable gives the relative proportion of the active links between two bodies in contact. This variable is chosen so that
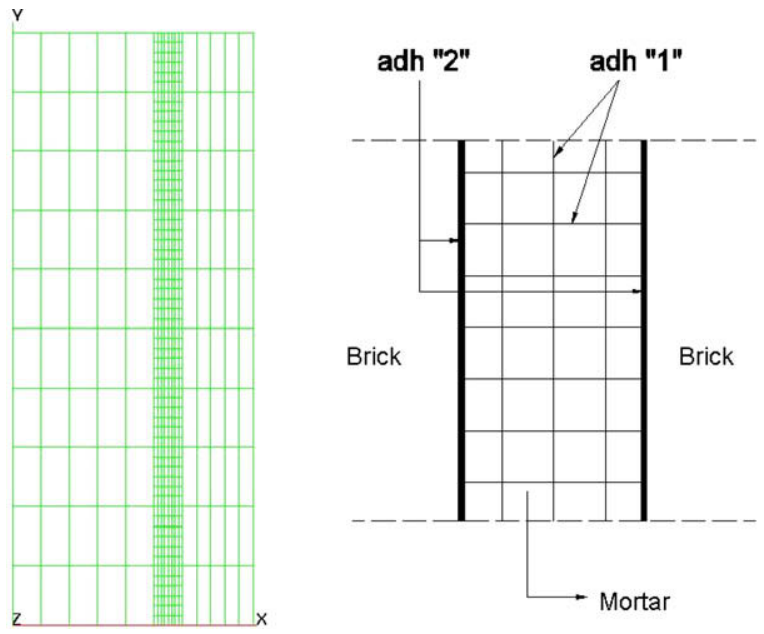

Fig. 12. Full-brick triplets: (a) mesh with cohesive mortar and (b) mortar/mortar and mortar/brick adhesion.

\section{$\beta=1, \quad$ totaladhesion \\ $0<\beta<1$, partialadhesion \\ $\beta=0$, noadhesion}

We are working in the framework of the contact between two deformable solids. The contact can be defined by a punctate correspondence between two surfaces in contact $\Gamma_{\mathrm{c}}^{1}$ and $\Gamma_{\mathrm{c}}^{2}$ of the domains $\Omega^{1}$ and $\Omega^{2}$ of $\mathbb{R}^{d}(d=2,3)$, respectively. At the initial time $t=t_{0}$, we assume that $\Gamma_{\mathrm{c}}=\Gamma_{\mathrm{c}}^{1}=\Gamma_{\mathrm{c}}^{2}$. The relative displacement between two points located on the two surfaces in contact is denoted by $[u]$ with $[u]=u^{1}-u^{2}$. Let $R$ be the density of the contact forces. We take $n^{1}$ and $n^{2}$ to denote the external unit normal vectors to the boundaries of the two domains. The decomposition into normal and tangential parts is written:

$[u]=\left[u_{N}\right] n^{1}+\left[u_{T}\right] \quad$ with $\left[u_{N}\right]=[u] \cdot n^{1}$

$R=R_{N} n^{1}+R_{T} \quad$ with $R_{N}=R \cdot n^{1}$

The state variables used for the thermodynamic description of this model are the strain tensor $\left(e_{i j}\right)$, the displacement jump $[u]$ and the intensity of adhesion $\beta$. Here we use the same notation as the previous authors $[8,13]: b$ is taken to denote the adhesion viscosity coefficient, $w$ to denote the Dupré energy, $\mu$ to denote the friction coefficient and $C_{N}$ (resp. $C_{T}$ ) to denote the initial normal (resp. tangential) stiffness of the interface. In what follows, $\dot{f}$ denotes the rate

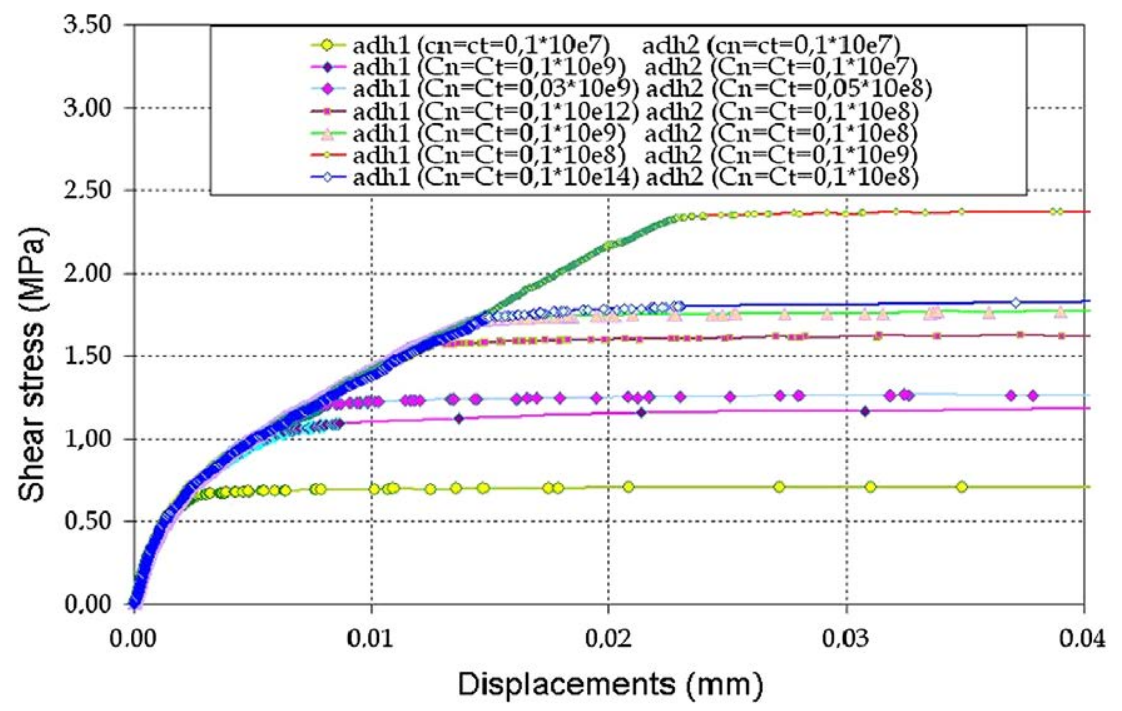

Fig. 13. Influence of the stiffness parameters on the behavior of the structure (triplets with a cohesive zone).
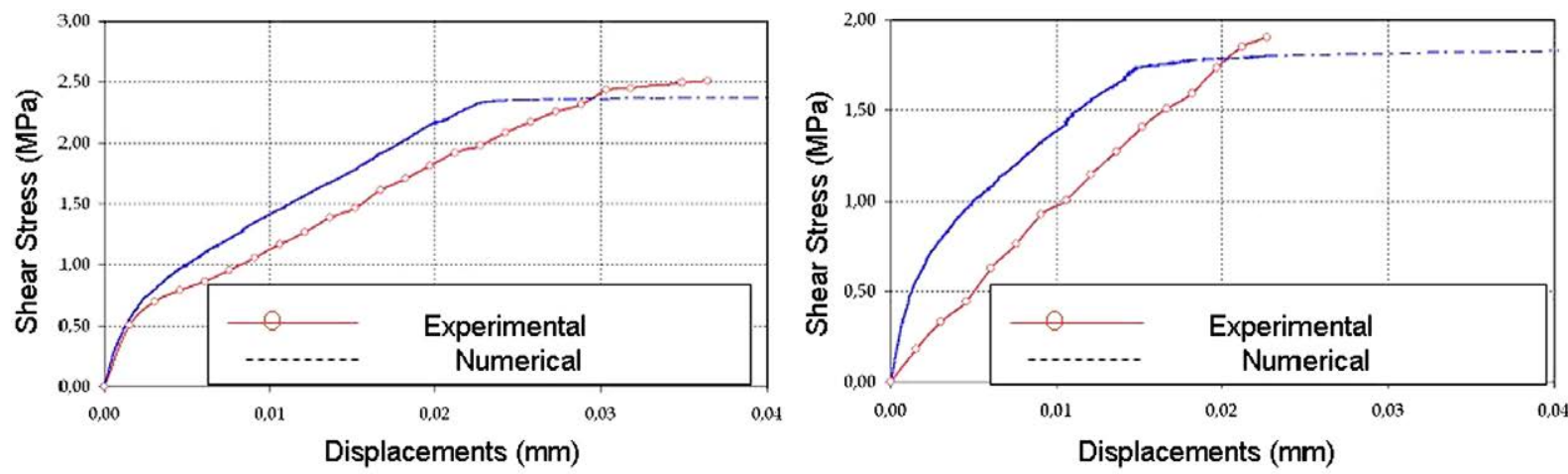

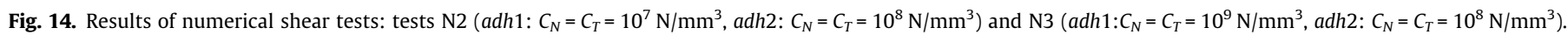


of the function $f$. The constitutive equations for the interface are based on state laws and complementarity laws:

\subsubsection{Unilateral contact with adhesion}

$R_{N}-C_{N}\left[u_{N}\right] \beta^{2} \geqslant 0 ; \quad\left[u_{N}\right] \geqslant 0 ; \quad\left(R_{N}-C_{N}\left[u_{N}\right] \beta^{2}\right)\left[u_{N}\right]=0$

\subsubsection{Friction with adhesion}

$$
\begin{aligned}
& \left\|R_{T}-C_{T}\left[u_{T}\right] \beta^{2}\right\| \leqslant \mu\left|R_{N}-C_{N}\left[u_{N}\right] \beta^{2}\right| \\
& \left\|R_{T}-C_{T}\left[u_{T}\right] \beta^{2}\right\|<\mu\left|R_{N}-C_{N}\left[u_{N}\right] \beta^{2}\right| \Rightarrow\left[\dot{u}_{T}\right]=0 \\
& \left\|R_{T}-C_{T}\left[u_{T}\right] \beta^{2}\right\|=\mu\left|R_{N}-C_{N}\left[u_{N}\right] \beta^{2}\right| \Rightarrow \exists \lambda \geqslant 0, \\
& {\left[\dot{u}_{T}\right]=\lambda\left(R_{T}-C_{T}\left[u_{T}\right] \beta^{2}\right)}
\end{aligned}
$$
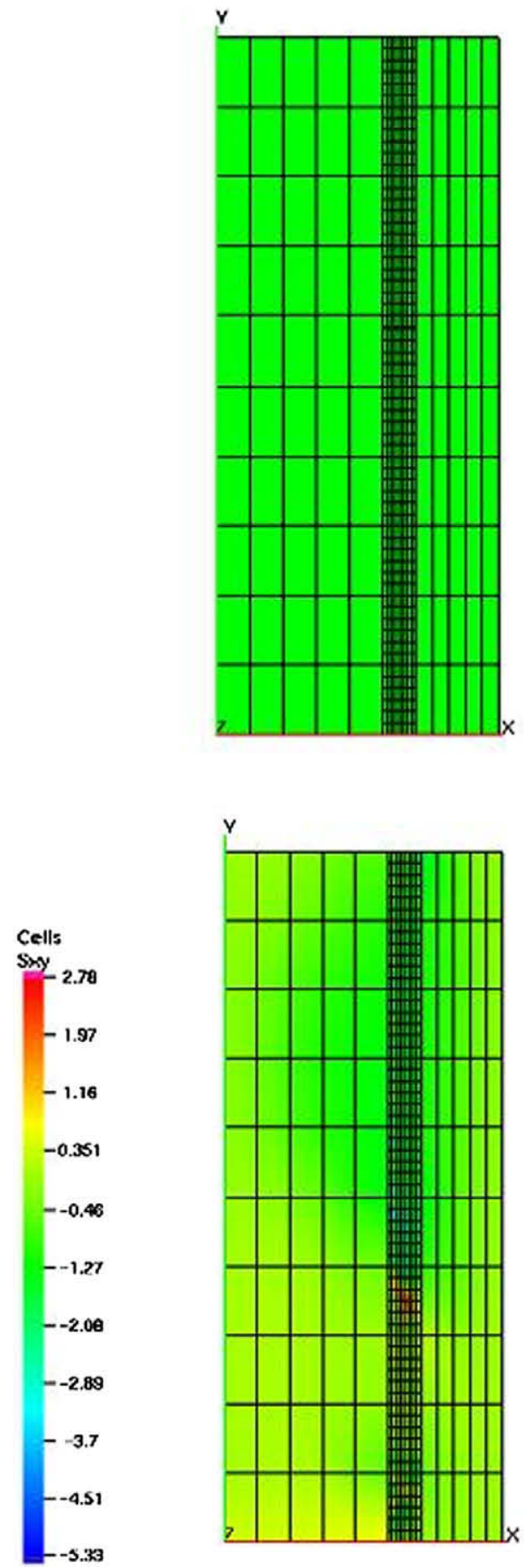

3.1.3. Evolution of the intensity of adhesion

$$
\begin{aligned}
& b \dot{\beta}=-\left(w-\left(C_{N}\left[u_{T}\right]^{2}+C_{T}\left|\left[u_{T}\right]\right|^{2}\right) \beta\right)^{-} \quad \text { if } \beta \in[0,1[ \\
& b \dot{\beta} \geqslant-\left(w-\left(C_{N}\left[u_{T}\right]^{2}+C_{T}\left|\left[u_{T}\right]\right|^{2}\right) \beta\right)^{-} \quad \text { if } \beta=1
\end{aligned}
$$

Note that if there is no adhesion $(\beta=0)$, this model involves the classical Signorini-Coulomb problem.

\subsection{Numerical processing}

The numerical problem was solved using the open computer code LMGC90 (http://www.lmgc.univ-montp2.fr/dubois/LMGC90/). This code is a numerical platform dedicated to the modelling and simulation of dynamic multibody problems. Various finite ele-
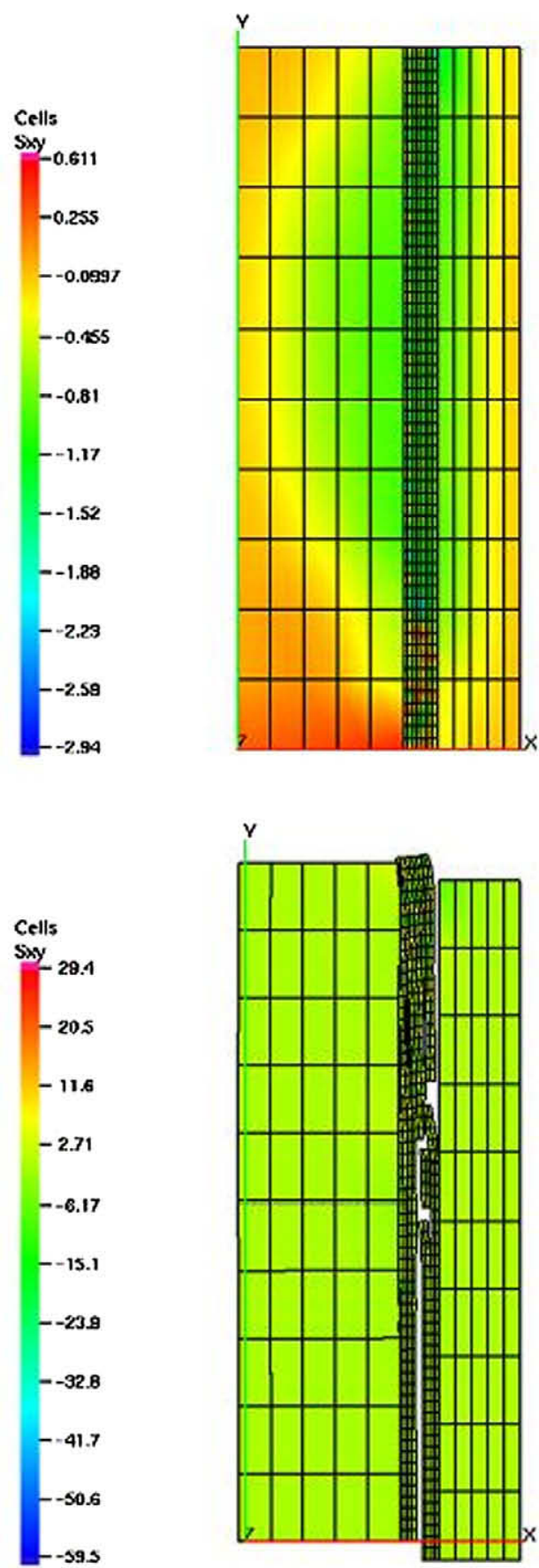

Fig. 15. Shear stress in full-brick triplets at steps $1,350,360$ and 371 (cohesive zone). 


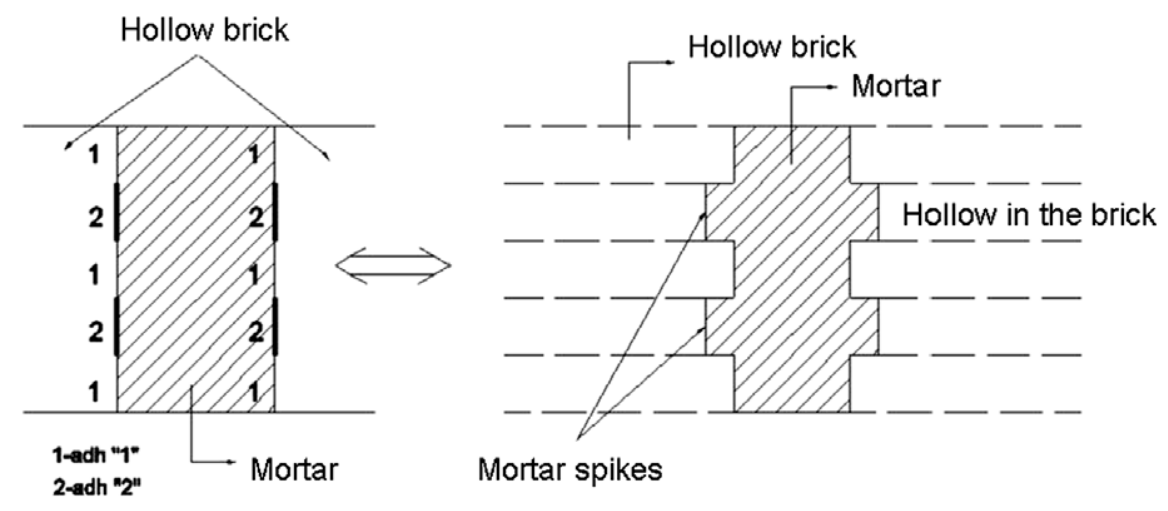

Fig. 16. Mortar spike modelling.
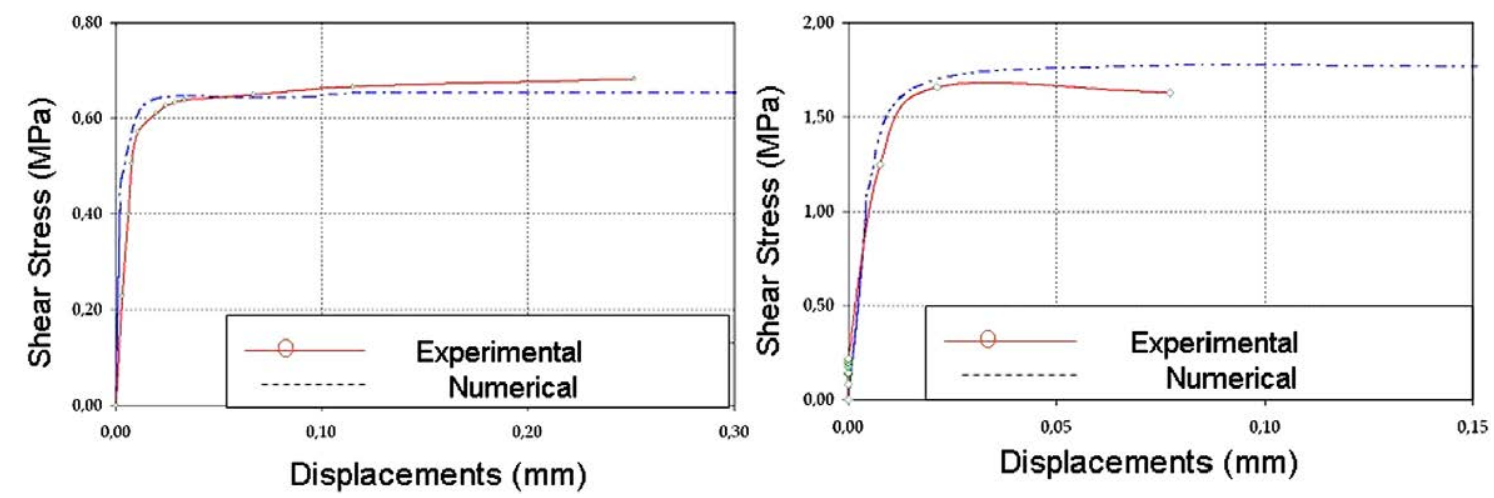

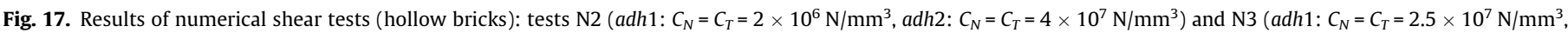
adh2: $C_{N}=C_{T}=1.5 \times 10^{8} \mathrm{~N} / \mathrm{mm}^{3}$ ).

ments have been implemented in this code [15] and various studies using this code have been published (these studies deal with diverse themes such as granular material, historical monument structures, biomaterials, etc.). These problems of this kind are usually approached using $\theta$-methods and the non-smooth contact dynamics (NSCD) method [16-18]. Due to the contact conditions, a fairly small time-step is chosen and the problem is condensed in the local frame associated with the contact nodes. The local problem is solved using a non-linear Gauss-Seidel method.

The interface is governed by the RCCM law presented above. Contact between bodies is defined by contact nodes. Contact nodes are located between two nodes in the mesh of an element in contact at distances of 0.2 and 0.8 along each segment in contact (Fig. 8).

In what follows, the bodies (bricks and mortar) are modelled using Q4 quadrangular finite elements. The numerical tests are performed with a constant time-step equal to $\Delta t=0.5 \times 10^{-3} \mathrm{~s}$. The computations require 2000 increments in order to reach values resembling the experimental data, and $\theta$ (in the time integration method) is fixed and taken to be equal to 0.55 .

\subsection{Mechanical behavior of small assemblages under shear loading conditions}

In this section, numerical simulations carried out with LMGC90 are presented. In particular, this study deals with the various assemblages (triplets and couplets consisting of full or hollow bricks) studied above in Section 2.2.

We will also cite other examples studied in the literature, such as the RILEM diagonal compression test, etc. It is attempted to model the same conditions as those pertaining in the experimental tests in terms of the geometries, mechanical characteristics, boundary conditions and loading conditions. The problems are treated under quasi-static conditions. The plane strain hypothesis is adopted here. As a matter of fact, the in-plane strains can be assumed to be negligible with respect to the plane strains.

For the sake of simplicity, the parameters used for the computations are: $\mu=0.2, b \approx 0, w=0.9 \mathrm{~J} / \mathrm{mm}^{2}$. Coefficients $C_{N}$ and $C_{T}$, the normal and tangential stiffness of the interface, will be determined in the following sections. These parameters will be obtained by comparing the experimental and numerical data.

The mechanical characteristics of the materials are as follows:

- Mortar: Young's modulus $4000 \mathrm{MPa}$, Poisson's ratio 0.3.

- Full bricks: Young's modulus $9439 \mathrm{MPa}$, Poisson's ratio 0.13.

- Hollow bricks: Young's modulus $6058 \mathrm{MPa}$, Poisson's ratio 0.13.

\subsubsection{Full-brick triplets}

The experimental data used here were those presented in Section 2. In the first part of this study, we noted the occurrence of two kinds of fracture processes, where

(1) the fracture occurs along the interface,

(2) the fracture begins along the interface and propagates into the mortar.

3.3.1.1. Fracture along the interface. The mesh consists of $130 \mathrm{Q} 4 \mathrm{fi}-$ nite elements. For the sake of symmetry, only the half-structure is studied here. The loading on the upper part ranges from 0 to $53 \mathrm{kN}$. The first step consists in determining the stiffness values of the interface, $C_{N}$ and $C_{T}$. Due to the shear loading, $C_{N}=C_{T}$ can be as- 
sumed. Various results on pairs of $C_{N}$ and $C_{T}$ are presented in Fig. 9. The global behavior can be seen to depend strongly on $C_{N}$ and $C_{T}$. The rigidity of the assembly depends mainly on the interface stiffness. Since the problem is highly non linear, even small perturbations in the stiffness coefficients can greatly affect the numerical responses.

The results shown in Fig. 10, which were obtained in tests numbers 1 and 4, are most encouraging, since the general shape of the curves is similar to that of the experimental curves. This confirms that the model accounts accurately for the mechanical behavior of the interface. This is also confirmed by the rupture modes obtained numerically (see Fig. 11). The variations in the shear stresses $\sigma_{x y}$ show that the stress concentration develops in the regions containing the discontinuities, or more specifically, at the level of the interface.

3.3.1.2. Cracks developing into the mortar. We now take the case where the interface and the mortar are fractured together. The results of the tests performed in this case are not as satisfactory as the previous ones. In the experimental part of this study, we noted that the cracks started to develop at the brick/mortar interfaces but continued into the mortar itself. It is therefore proposed to intro-
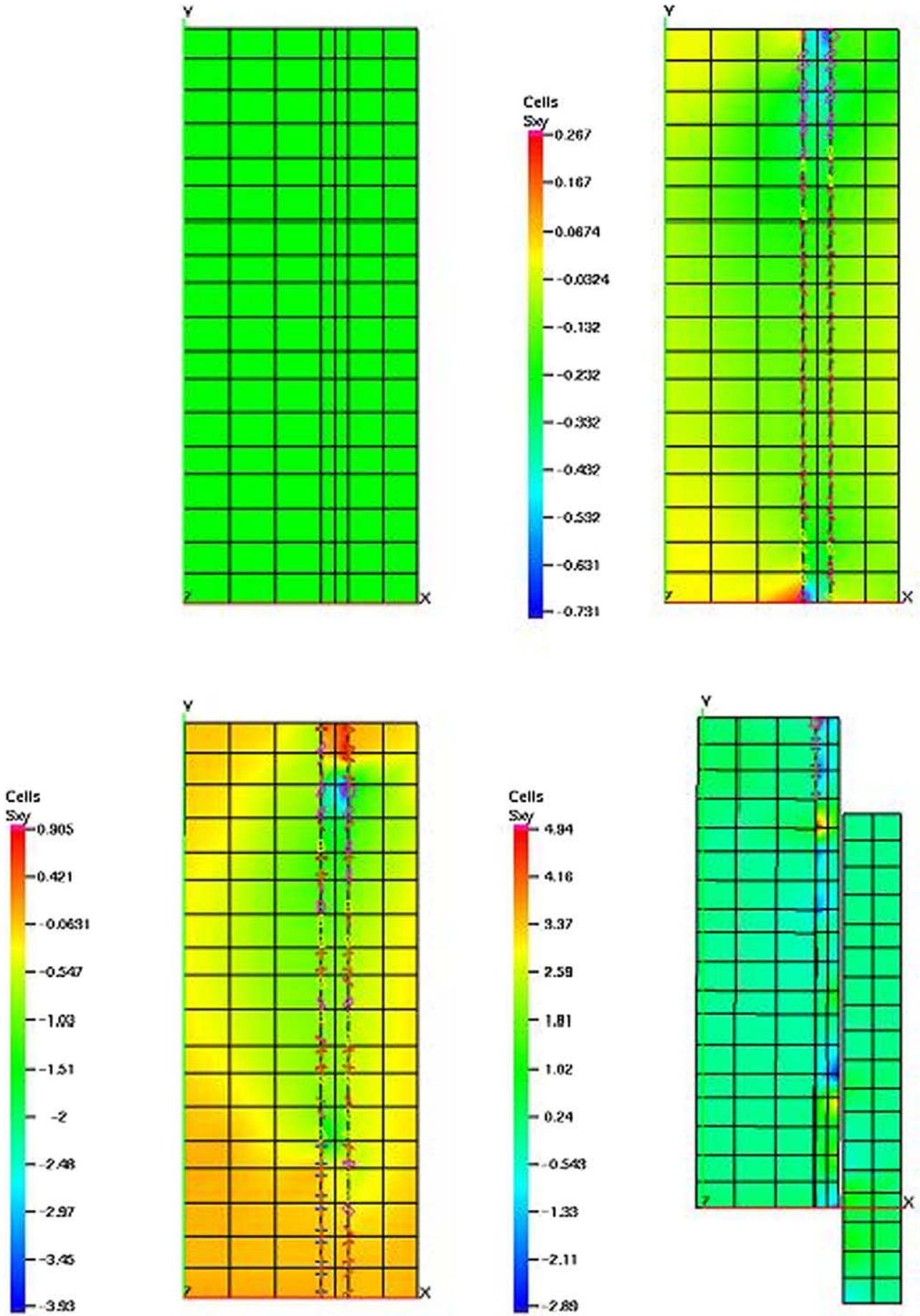

Fig. 18. Shear stress in hollow-brick triplets at steps 1, 53, 191 and 196. 


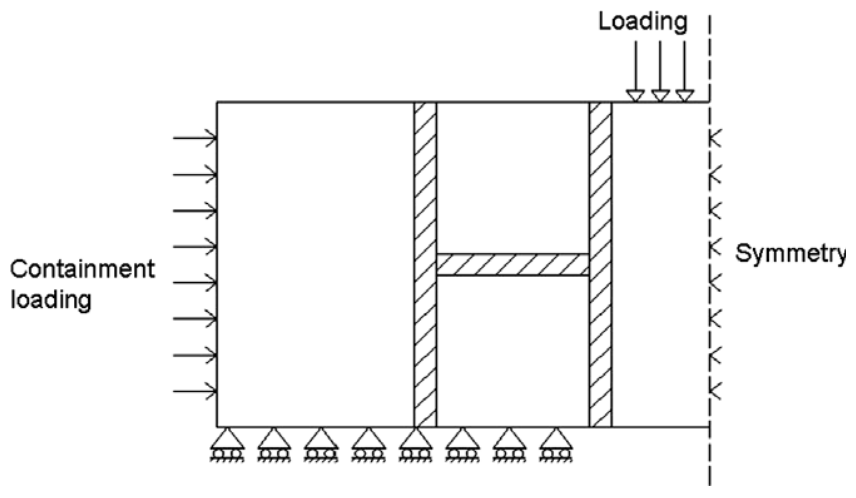

Fig. 19. Small wall modelling.

duce the damage to the mortar using a cohesive zone model. The mortar is split into sub-bodies. Each sub-body is meshed using a quadrangular mesh with Q4 finite elements (Fig. 12). The contact between sub-bodies is governed by the RCCM model. We take adh 1 and adh 2 to denote the law of adherence at the mortar/mortar and the brick/mortar interface, respectively (Fig. 12).

It can be seen from Fig. 13 that the behavior of the structure is sensitive to changes in the stiffness coefficients.

The numerical results are in good agreement with the experimental data from the qualitative point of view. They show the degradation of the rigidity induced by the propagation of the crack into the mortar in the two experimental tests 2 and 3 (Fig. 14). The model predicted the similar occurrence of cracks in the mortar joint to those observed in practice (Fig. 15).

\subsubsection{Hollow-brick assemblages}

In the case of hollow-brick structures, the experimental data show that the behavior of the material at the interface is quite different between the hollow parts of the brick and the full parts. At the level of the hollow parts, spikes of mortar penetrate into the voids of the brick. It is therefore necessary to distinguish between
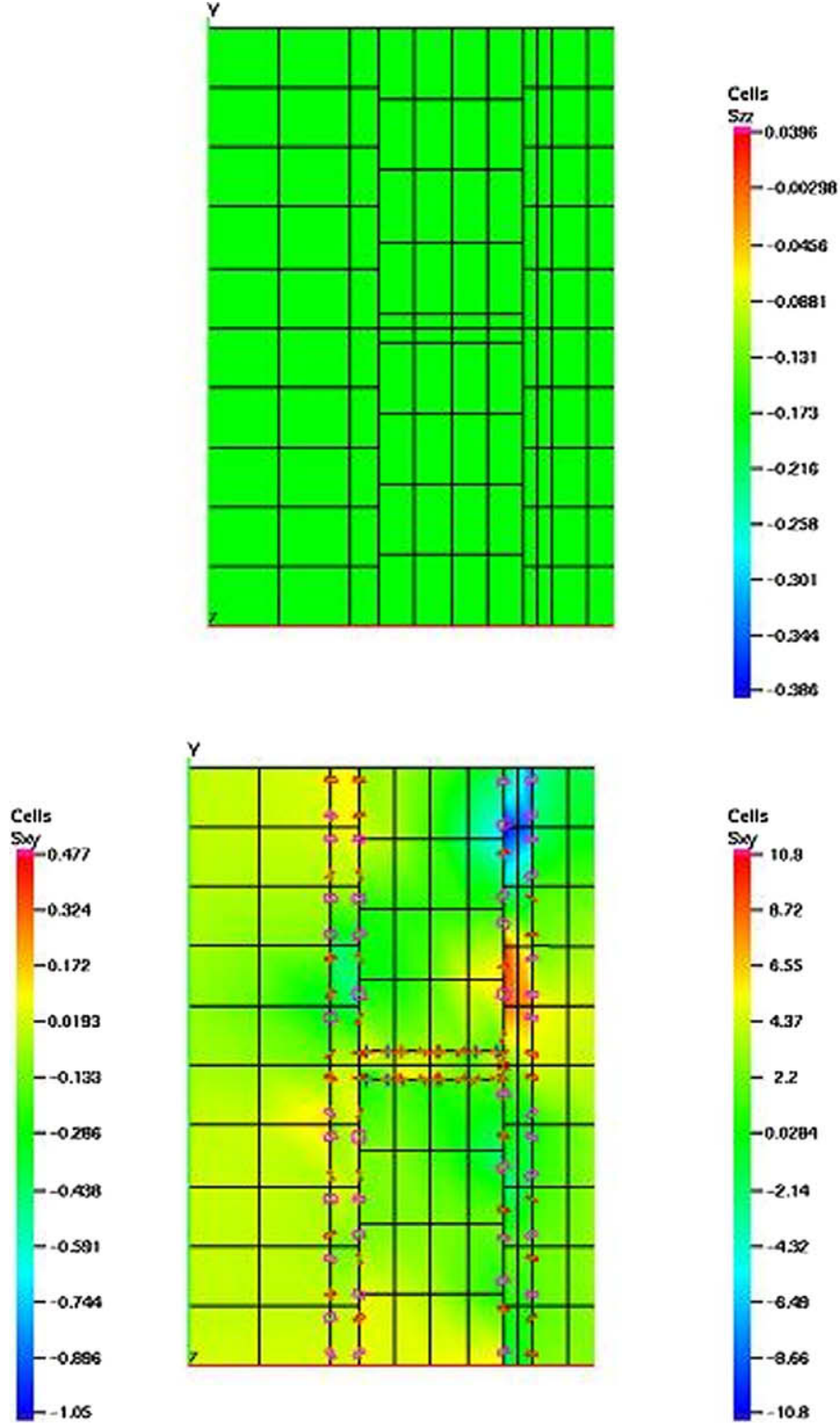
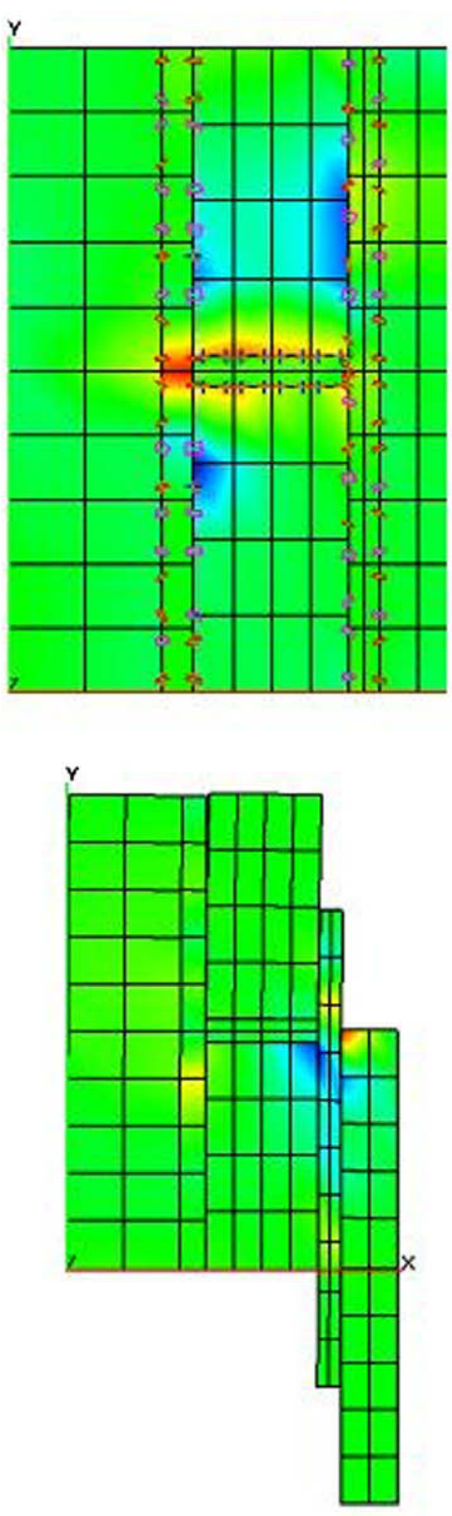

Fig. 20. Small wall: changes in the structure. 
two zones: the zone (adh1) corresponding to the mortar/brick interface as in the case of full-brick structures and the second zone (adh2) corresponding to the spikes. Fig. 16 shows these two zones.

By suitably choosing the stiffness coefficients, this strategy makes it possible to approach the experimental results, as can be seen from Fig. 17. However, it is necessary to find several coefficients, which reduces the efficiency of the method. This situation could possibly be improved by averaging the two zones, but this approach has not yet been attempted. The changes with time in the shear stress and in the deformed structure are shown in Fig. 18.

\subsubsection{Other examples}

3.3.3.1. A small assembly. In this section, we deal with an example available in the literature [19], that of a small structure consisting of seven bricks (Fig. 19). Because of the symmetry, only the halfstructure is included here in the computations. A containment load
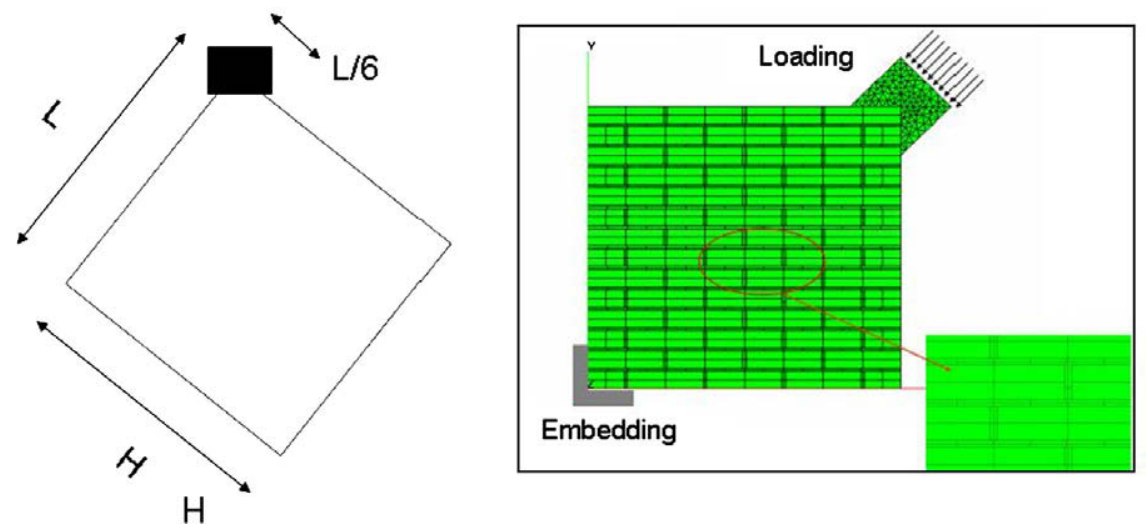

Fig. 21. Diagonal compression: dimensions $(H=840 \mathrm{~mm}, L=870 \mathrm{~mm})$ and mesh.
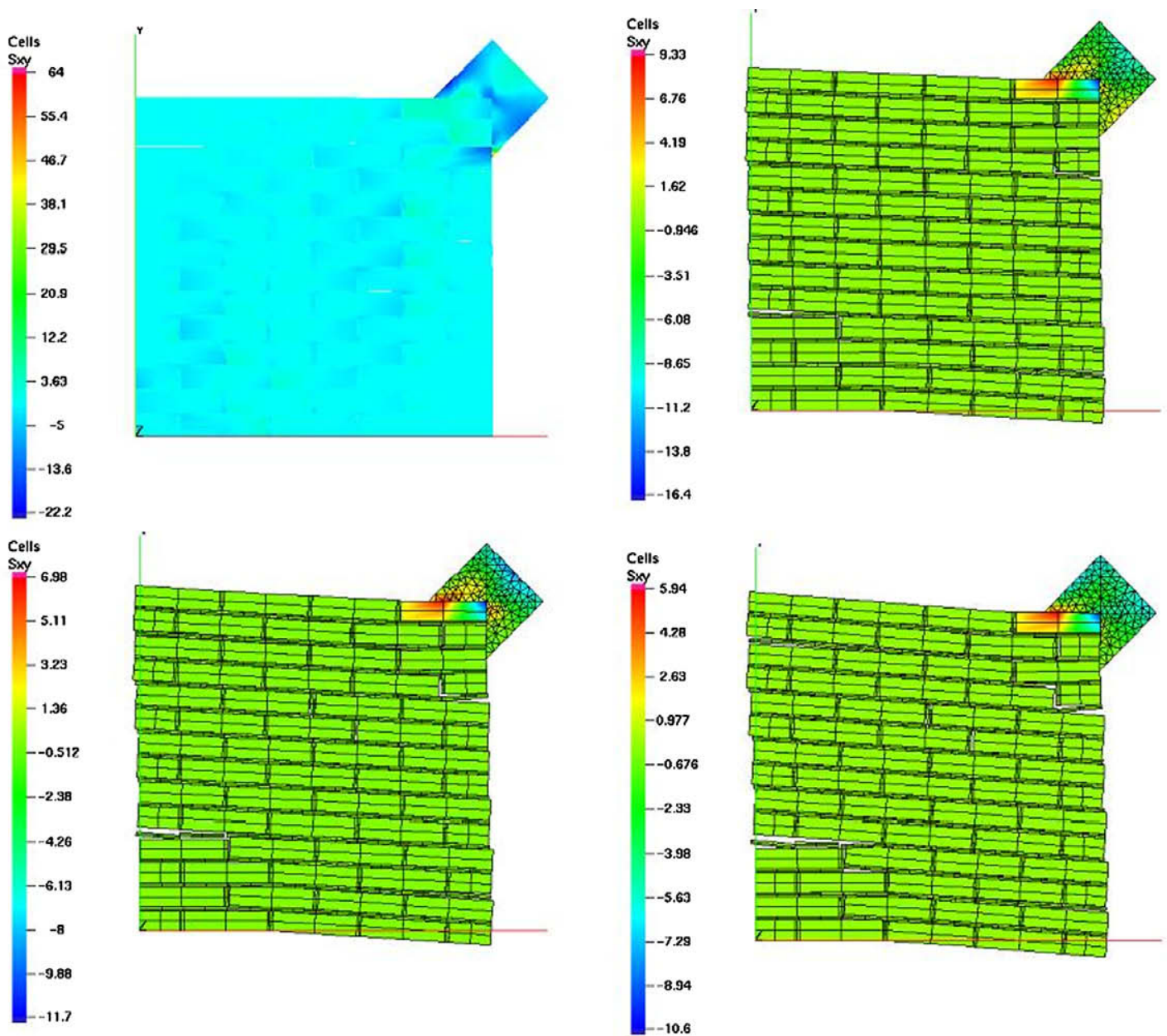

Fig. 22. Diagonal compression: changes in the structure at steps 1, 347, 370 and 401. 
is first applied to the vertical left face, and a vertical load is then applied to the central brick. The characteristics used in the numerical test are as follows:

- $\mu=0.2$

- $b \approx 0$,

- $w=0.9 \mathrm{~J} / \mathrm{mm}^{2}$,

- $C_{N}=C_{T}=4 \times 10^{6} \mathrm{~N} / \mathrm{mm}^{3}$.

The evolution of the shear stress and the deformed structure from the initial position to rupture are given in Fig. 20 .

The behavior of this assemblage is a fragile behavior. Two phases were observed:

- the first phase continues until the crack is very stiff,

- the second phase corresponds to the sliding between brick and the neighbouring brick.

This finding is in agreement with the experimental data. The containment load induces a slight softening. This example was the first attempt to deal with more complex and realistic structures.

3.3.3.2. Diagonal compression of a small wall. This section deals with the numerical modelling of a diagonal compression test performed on a wall (see Fig. 21). The wall under investigation is embedded at one corner and a uniform load is applied to the opposite corner. The load is evolutive until the rupture of the wall occurs. The dimensions of the wall were chosen in line with the RILEM recommendations [20] on tests of this kind. The shape of the wall was taken to be almost square. In the numerical modelling procedure, we simulated the boundary conditions, loading and geometry as described by Gabor $[19,21]$. The structure is composed of full bricks measuring $210 \times 50 \mathrm{~mm}^{2}$, and the mortar is $10 \mathrm{~mm}$ thick. The wall measures $870 \times 840 \mathrm{~mm}^{2}$ (see Fig. 21). The mechanical characteristics [19] are as follows: Young's modulus $16.7 \mathrm{GPa}$ (brick) and $1.028 \mathrm{GPa}$ (mortar); Poisson's ratio 0.15 (brick) and 0.125 (mortar) [19]. The structure is discretized using quadrangular elements (Q4). The wall is split into 217 parts (bricks and mortar), corresponding to a total number of 868 finite elements (see Fig. 21). The RCCM adhesion model was introduced at the mortar/bricks interface. In order to model the rupture process in the mortar, the mortar is decomposed into substructures and the RCCM adhesion model was introduced along with other mechanical coefficients at the mortar/mortar interface (cohesive zone model). The two adhesion laws are denoted $a d h 1$ and adh2. The mortar was modelled in this way because of the rupture modes observed in the wall: a crack propagates diagonally along the wall. However, the bodies composing the mortar have other characteristics, which
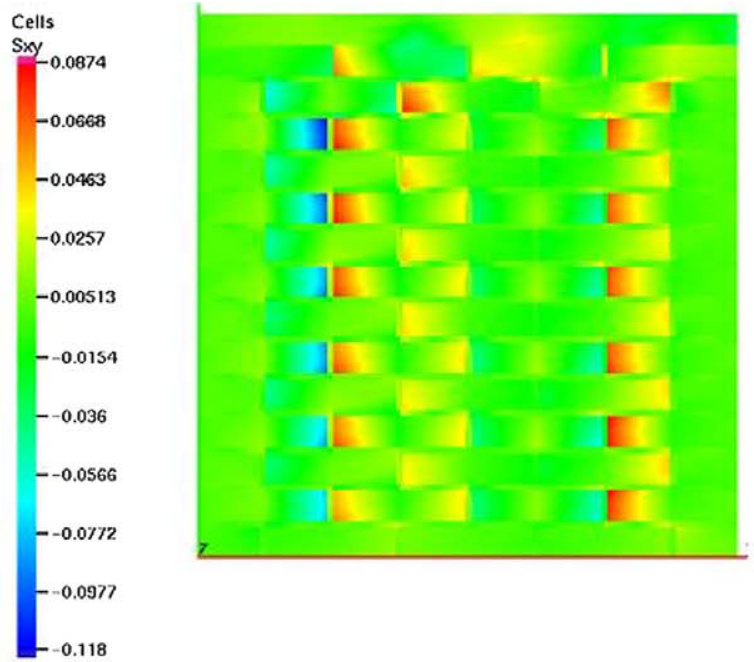

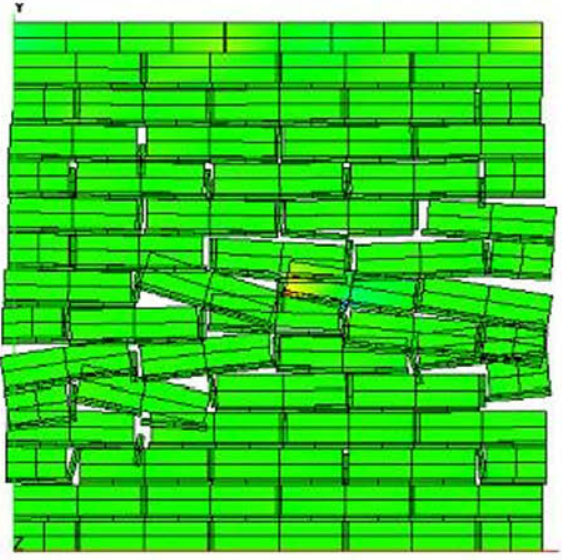

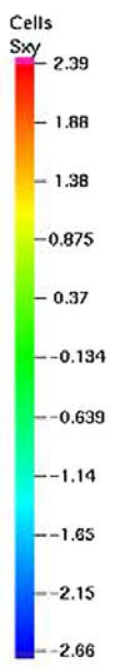
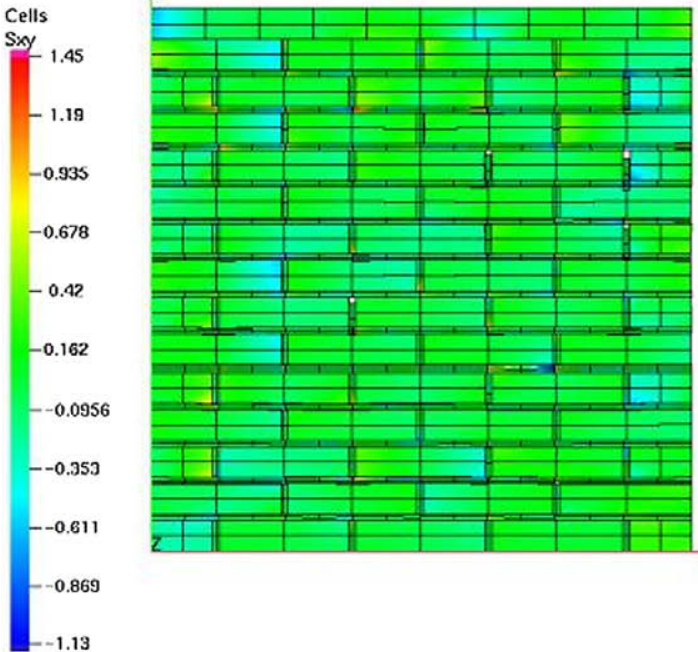

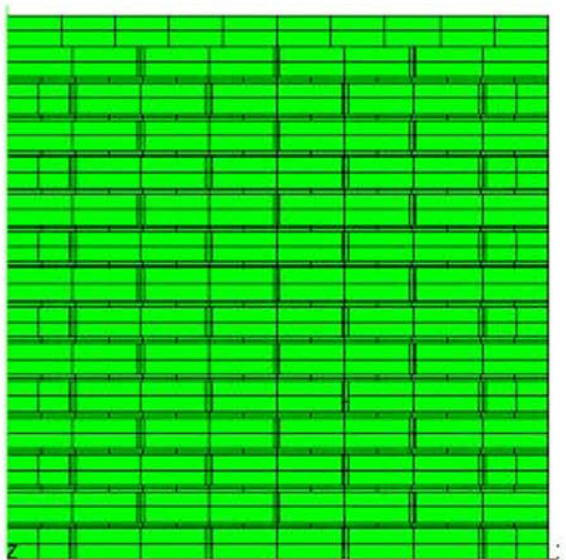

Fig. 23. Mixed loading: behavior of the structure. 
usually have larger values than those of the mortar/brick interface. These values are as follows:

$$
\text { Mortar/brick interface } \mu=0.2, w=0.9 \mathrm{~J} / \mathrm{mm}^{2} \quad C_{N}=10^{6} \mathrm{~N} / \mathrm{mm}^{3} \text {, }
$$$$
C_{T}=10^{6} \mathrm{~N} / \mathrm{mm}^{3} \text {, }
$$

Mortar/mortar interface $\mu=0.2, w=0.9 \mathrm{~J} / \mathrm{mm}^{2} \quad C_{N}=30 \times 10^{6} \mathrm{~N} /$ $\mathrm{mm}^{3}, C_{T}=30 \times 10^{6} \mathrm{~N} / \mathrm{mm}^{3}$.

A very small coefficient $b$ was adopted.

The numerical results obtained in the case of this example show the propagation of a crack along the compressed diagonal. The fracture is due to the shear stress concentration occurring along the diagonal (Fig. 22). From the qualitative point of view, these results match those obtained experimentally in [19], even with a rather coarse discretization step.

\subsubsection{Mixed loading: superimposition of compression and shear on a small wall}

In this section, the structure presented in the previous section is subjected to another kind of loading. The test is carried out in two steps: a vertical load of $120 \mathrm{kN}$ is first applied to the upper part of the structure and a horizontal punctual force of $65 \mathrm{kN}$ is then applied at the upper left corner of the structure.

Rupture modes occurring along the diagonal were obtained as shown in Fig. 23. This example confirms that this method is applicable to complex structures.

\section{Conclusion}

The adhesion model presented in Section 3.2 was successfully used in this study to simulate the experimental tests described in Section 2, which provided the coefficients required to model the interface: stiffness parameters, viscosity coefficient, Dupré's energy and friction coefficient. The model is sensitive to these characteristics but the results obtained are in line with the experimental data.

The two kinds of rupture modes observed experimentally were described using two different adhesive characteristics. It was thus possible to model the fracture process occurring along the interface as well as that involving the mortar.

Structures composed of hollow bricks can also be modelled in this way using two adhesive characteristics. In particular, the model was used here to study the fracture process occurring along the interface of a small structure consisting of three hollow bricks. Further studies are now required on the fracture processes crossing the mortar in structures of this kind.

The present method was also tested on more complex structures presented in the literature. The results obtained show that it is possible with this model to accurately describe the behavior of structures of this kind. In particular, the cracking of the mortar in a small wall structure was accurately predicted by the model.

It is now proposed to study more complex structures such as modern masonry buildings. Another project consists in developing models of other kinds accounting for other processes, such as the crack processes occurring on the microscopic scales.

\section{References}

[1] Orduna A, Lourenço PB. Three-dimensional limit analysis of rigid blocks assemblages. Part II: load-path following solution procedure and validation. Int J Solids Struct 2005;42:5161-80.

[2] Lourenço PB, Barros JO, Olveira JT. Shear testing of stack bonded masonry. Construct Build Mater 2004;18:125-32.

[3] Anthoine A, Magonette G, Magenes G. Shear-compression testing and analysis of brick masonry walls. In: Duma G, editor. Proceeding of the 10th European conferences on earthquake engineering, vol. 3. Rotterdam: Balkema; 1995. p. 1657-62.

[4] Benedetti D, Benzoni GM. A numerical model for seismic analysis of masonry building: experimental correlations. Earthquake Eng Struct Dyn 1984;12: 817-31.

[5] Del Piero G. Constitutive equation and compatibility of the external loads for linearly elastic masonry-like materials. Meccanica 1987;24:150-62.

[6] Lotfi HR, Shing PB. An appraisal of smeared crack models for masonry shear wall analysis. Comput Struct 1991;41:413-25.

[7] Gambarotta L, Lagomarsino S. Damage models for the seismic response of brick masonry shear walls. Part I: the mortar joint model and its applications. Earthquake Eng Struct Dyn 1997;26:42339.

[8] Raous M, Cangémi L, Cocou M. A consistent model coupling adhesion, friction and unilateral contact. Comput Methods Appl Mech Eng 1999;177:383-99.

[9] Gabor A. Contribution à la caractérisation et à la modélisation des maçonnerie non renforcées et renforcées par matériaux composites. PhD thesis, Université Claude Bernard Lyon 1; 2002.

[10] NF EN 772-1. Norme Européenne, Norme Française, Méthodes d'essai des éléments de maçonnerie - Partie 1: détermination de la résistance à la compression; 2001.

[11] NF EN 1052-3. Norme Européenne, Norme Française, Méthodes d'essai de la maçonnerie - Partie 3: détermination de la résistance initiale au cisaillement; 2003.

[12] Francfort G, Marigo J-J. Revisiting brittle fracture as an energy minimization problem. J Mech Phys Solids 1998;80:1319-42.

[13] Monerie Y, Raous M. A model coupling adhesion to friction for the interaction between a crack and a fiber/matrix interface. Z A M M 2000;80:205-9.

[14] Frémond M. Adhérence des solides. J Mec Theor Appl 1987;6:383-407.

[15] Stainier L, Dubois F, Peyroux R. Matlib, Une bibiliothèque portable de modèles constitutifs pour la mécanique non-linéaire des solides: concepts et implémentation. In: 16ème French CSMA Conf. Giens; 2003, p. 20-3.

[16] Moreau JJ. On unilateral constraints friction and plasticity. In: Capriz G, Stampacchia G, editors. New variational techniques in mathematical physics. CIME II ciclo, vol. 302. Edizioni Cremonese; 1973. p. 175-322.

[17] Moreau JJ. Unilateral contact and dry friction in finite freedom dynamics. In: Moreau JJ, Paanagiotopoulos PD, editors. Nonsmooth mechanics and applications. CISM courses and lectures, vol. 302. Springer-Verlag; 1988. p. $1-82$.

[18] Jean M. Frictional contact in rigid or deformable bodies: numerical simulation of geomaterials. Amsterdam: Elsevier Science Publisher; 1995. p. 463-86.

[19] Gabor A, Ferrier E, Jacquelin E, Hamelin P. Analysis of the inplane shear behaviour of FRP reinforced hollow brick masonry walls. Struct Eng Mech 2005;19:237-60.

[20] LUMB6. Diagonal tensile strength tests of small wall specimens. Technical Report, RILEM; 1994.

[21] Gabor A, Bennani A, Jacquelin E, Lebon F. Modelling approaches of the in-plane shear behaviour of unreinforced and FRP strengthened masonry panels. Comput Struct 2006;74:277-88. 